ఠ

OPEN ACCESS

EDITORAS

- Claudia Wanderley (UNICAMP)

- Anna Christina Bentes (UNICAMP)

\section{AVALIADORES}

- Silmara Dela Silva (UFF)

- Luiz Rocha (UFJF)

SOBRE OS AUTORES

- Rodrigo Esteves de Lima-Lopes Curadoria de Dados, Análise Formal, Metodologia, Software, Supervisão, Escrita - Análise e Edição.

- Karen Tank Mercuri

Conceptualização, Curadoria de Dados, Análise Formal, Escrita -

Rascunho Original, Escrita - Análise e Edição.

- Maristella Gabardo

Conceptualização, Análise Formal,

Escrita - Análise e Edição.

DATAS

- Recebido: 28/05/2020

- Aceito: 21/12/2020

- Publicado: 02/03/2021

\section{COMO CITAR}

LIMA-LOPES, R.E.; MERCURI, K.T.; GABARBO, M. (2020). Avaliatividade em comentários sobreem postagens dedicadas à verificação de notícias falsas nas Eleições Presidenciais de 2018. Cadernos de Linguística, v. 1, n. 4, p. 01-25.

\title{
AVALIATIVIDADE EM \\ COMENTÁRIOS SOBRE POSTAGENS DEDICADAS À VERIFICAÇÃO DE NOTIÍCIAS FALSAS NAS ELEIÇÕES PRESIDENCIAIS DE 2018
}

\author{
Rodrigo Esteves de LIMA-LOPES (D) \\ Instituto de Estudos da Linguagem - Universidade Estadual \\ de Campinas (UNICAMP) \\ Karen Tank MERCURI (D) \\ Instituto de Estudos da Linguagem - Universidade Estadual \\ de Campinas (UNICAMP) \\ Maristella GABARDO (D) \\ Instituto Federal do Paraná (IFPR) | Universidade Estadual \\ de Campinas (UNICAMP)
}

RESUMO

Este artigo tem por objetivo estudar os comentários realizados por usuários de uma mídia social em resposta a quinze postagens de uma agência verificadora de fatos às vésperas do segundo turno das eleições de 2018. A relevância desse estudo se encontra na constatação de que além de sua grande proliferação, as fake news assinalam a sua influência para a criação de um mundo pós-verdade, no qual posicionamentos pesam mais do que fatos. Nossas bases teóricas associadas a esta análise estão na Linguística Sistêmico-Funcional, mais especificamente no Sistema de Avaliatividade. A coleta de dados foi realizada por meio de ferramentas automáticas de raspagem sendo processadas por meio de 
programas escritos na linguagem $\mathrm{R}$. As análises se pautam na rede de colocados que se forma, as frequências de usos e as relações entre eles que nos levam a identificar padrões dentro das argumentações propostas nos comentários. Essas percepções são complementares à análise da gramaticalização das hashtags e seus múltiplos usos dentro das linhas argumentativas apresentadas pelos usuários. Os resultados mostram que os comentários não trazem reflexões sobre o conteúdo dos fatos desmentidos pela agência, sendo comum o discurso de polarização política, utilizando métodos argumentativos específicos, como a prova por contradição.

\section{ABSTRACT}

This article aims to study the comments made by users of a social media in response to 15 posts from a fact-checking agency the second round of the 2018 elections. The relevance of this study is to observe the influence of fakenews in the creation of a post-truth discourse, in which positions weigh more than facts. Our theoretical bases analysis are in SystemicFunctional Linguistics, more specifically in the evaluation system. Data collection was performed using automatic scraping tools, and data was processed using programmes written in the $\mathrm{R}$ language. The analyses are based on the network of collocates, the use frequency of words and in the relationships such words show. Such methods lead us to identify patterns within the arguments proposed in the comments, mostly based on political pre-formed perceptions. These perceptions are complementary to the grammatical analysis of hashtags and their multiple uses within the lines of argument present. The results show that the comments do not bring reflections upon the facts checked by the agency, and the political polarization discourse is common, using specific argumentative methods, such as proof by contradiction.

\section{PALAVRAS-CHAVE}

Fake News; Linguística Sistêmico-Funcional; Avaliatividade; Linguística do Corpus.

\section{KEYWORDS}

Fake News; Systemic-Functional Linguistics; Appraisal; Corpus Linguistics. 


\section{INTRODUÇÃO}

Este artigo tem por objetivo analisar 851 comentários colhidos em resposta a 15 postagens da agência verificadora de notícias Fato ou Fake em sua página oficial no Facebook¹ sob a luz da Avaliatividade (MARTIN; WHITE, 2005), que tem suas bases na Linguística SistêmicoFuncional, doravante LSF (HALLIDAY, 1978).

A LSF é uma teoria de cunho semântico-social que busca compreender como a linguagem reflete questões sociais e de uso, caracterizando-se por ser uma abordagem pós-saussureana (HASAN, 2014; KRESS, 1993; STUBBS, 1996). Em outras palavras, a LSF parte da perspectiva de que o significado é motivado em todos os níveis de instanciação, estrutura e significação, os quais são inseparáveis. Assim, o significado é motivado contextualmente pela relação entre as diferentes escolhas léxico-gramaticais, o que torna a instanciação linguística o único parâmetro para a criação de signos.

O Sistema de Avaliatividade, por seu turno, foi desenvolvido como ferramenta de análise dos processos de julgamento e apreciação comuns à linguagem (MARTIN; WHITE, 2005).

Os processos metodológicos estão baseados na Linguística do Corpus (ESIMAJE; HUNSTON, 2019; SHAROFF, 2017; TUMBE, 2019). Essa abordagem permite o processamento de dados em grande escala e possibilita a análise exaustiva das associações lexicais e itens avaliativos levantados. Os dados deste trabalho foram processados utilizando-se a linguagem de programação R. Programas e funções específicas para o tratamento do corpus foram escritos e serão disponibilizadas pelos pesquisadores para comunidade.?

O termo notícias falsas (fake news) foi cunhado para identificar quaisquer publicações que possam ser verificavelmente falsas e possam levar os leitores a enganos e falsas interpretações (ALLCOTT; GENTZKOW, 2017). Por falsas entendem-se informações incompletas, manipuladas, incoerentes, exageradas, pautadas em fontes não confiáveis ou que contenham propaganda ideológica ou de produtos (TANDOC; LIM; LING, 2018). No contexto da comunicação mediada pela internet, a produção de notícias falsas é motivada por dois objetivos. O primeiro seria o ganho financeiro gerado pela quantidade de cliques que ela atrai, ao passo que o segundo seria o favorecimento de uma certa ideia, grupo ou pessoa de forma direta e/ou indireta (ALLCOTT; GENTZKOW, 2017; TANDOC; LIM; LING, 2018). De acordo com Khriyenko (2018), um dos principais objetivos da guerra gerada pelas fake news é criar o caos, não havendo congruência entre as informações divulgadas, gerando uma confusão generalizada na sociedade (KHRIYENKO, 2018). Advém daí a relevância de se estudar as reações e os comentários que os usuários de uma

1 Disponivel em: <https://www.facebook.com/fatooufake>. Acesso em 17 out. 2018.

2 Disponível em: https://github.com/rll307/ArtigoFatoFake 
mídia social apresentam ao terem acesso à informação de que uma determinada notícia é falsa, duvidosa, enganosa ou gera desinformação.

De forma a realizar tal objetivo, este artigo é dividido em quatro outras seções. Na primeira, discutiremos o sistema de avaliatividade e algumas pesquisas relacionadas à aplicação dessa teoria à língua portuguesa. Segue-se a seção metodologia, que traz os procedimentos de coleta e análise, assim como uma descrição do corpus de pesquisa e seu contexto. A análise de dados traz reflexões sobre os resultados da pesquisa, sendo que este artigo se encerra com as considerações finais.

\section{O SISTEMA DE AVALIATIVIDADE}

O processo de avaliar é intrínseco ao humano e é um instrumento de construção e negociação de valores socialmente compartilhados (OLIVEIRA, 2014). A todo momento, avaliamse pessoas, coisas e fatos de acordo com crenças, valores e intenção comunicativa de uma comunidade em um determinado contexto. Segundo Thompson e Alba-Juez (2014), seria difícil estudar sistemas de valores humanos sem recorrer à análise linguística, porque a função avaliativa é uma das funções básicas e importantes da linguagem e, portanto, vale a pena ser investigada em profundidade (THOMPSON; ALBA-JUEZ, 2014).

Na mesma direção, Martin e White (2005), desenvolveram o Sistema de Avaliatividade, inscrito no eixo teórico da LSF (HALLIDAY; MATTHIESSEN, 2004). A proposta inicial de Martin e White (2005) é que tal sistema estaria ligado à metafunção interpessoal, já que as avaliações presentes nos textos têm a função de estabelecer relações entre o escritor/falante e o leitor/ouvinte. No contexto da LSF, o termo sistema faz referência a um conjunto de escolhas no nível semântico-discursivo, com uma forma relação de dependência do contexto em que se está inserido. Já a Avaliatividade refere-se ao potencial semiótico que a linguagem oferece para expressar pontos de vista e realizar significados avaliativos (positivos ou negativos), atribuindo, ainda, força e foco ao que é expresso (VIAN JR, 2009). Consequentemente, ao fazer essa escolha, os escritores/falantes marcam sua posição no texto quando se expressam, construindo para seus discursos um público ideal. Embora elaborado para a língua inglesa, não se descarta "analisar como esses mecanismos ocorrem na Língua Portuguesa" (VIAN JR, 2009, p. 19).

Neste artigo, além das peculiaridades da língua portuguesa, deve-se considerar também o ambiente em que essas manifestações linguísticas acontecem: as mídias sociais, onde não há, em geral, preocupação com o padrão formal da língua e há abreviações das mais diversas formas, bem como neologismos e hashtags gramaticalizadas (LIMA-LOPES, 2019), as quais compõem a estrutura da oração. Considerando ainda que, se o corpus trata de discussões políticas, o Sistema da Avaliatividade dará o aporte necessário para a 
compreensão das avaliações (julgamentos e expressões de afeto) presentes no texto e que marcam a posição do escritor. Essas marcas podem indicar: aprovação/desaprovação, carinho/ódio, elogios/críticas a seres e fatos tanto do contexto social-cultural como do contexto de situação. Sendo assim, qualquer escolha no nível léxico-gramatical resultará em uma escolha no nível semântico-discursivo.

Uma vez identificadas as marcas avaliativas, estas são classificadas de acordo com Sistema de Avaliatividade (MARTIN; WHITE, 2005). Nesse método, há categorizações em vários níveis, sendo as três principais (de primeiro nível): Atitude (as avaliações são de que tipo?), Engajamento (há dialogismo com outros textos?) e Gradação (qual é a força e foco com que é apresentada a avaliação?). Dentre essas categorias, o subsistema Atitude será o utilizado neste artigo, pois se adequa melhor aos objetivos de pesquisa.

A Atitude é a posição que é assumida perante algo ao se avaliar o mundo e expressá-lo na linguagem, com sentimento positivo ou negativo. Ela é dividida em três regiões semânticas: Afeto (avaliação dos sentimentos humanos), Julgamento (avaliação das ações humanas) e Apreciação (avaliação das qualidades estéticas) (MARTIN; WHITE, 2005). Mais especificamente, o Afeto é um recurso para avaliar os sentimentos, com carga semântica positiva ou negativa, expressos explícita ou implicitamente; pode expressar ou atribuir qualidades a participantes ou processos (ALMEIDA, 2011). Já os julgamentos podem ser sobre legalidade, moralidade, normalidade e capacidade, os quais dependem da cultura, normas e crenças particulares em uma situação ideológica. A apreciação envolve avaliações sobre o valor das coisas e fenômenos semióticos e naturais, em um campo específico. Martin e White (2005) propõem conjuntos nos quais Afeto, Julgamento e Apreciação seriam agrupados: (i) Afeto (in)felicidade, (in)segurança e (in)satisfação; (ii) Julgamento - de estima e de sanção; (iii) Apreciação - reação, composição e valoração.

Mais especificamente, podemos definir os subsistemas de Afeto, Julgamento e Apreciação, conforme segue. Primeiramente, o subsistema Afeto: (i) Felicidade/infelicidade: sentimentos relacionados a emoções pessoais que podem tornar uma pessoa feliz ou infeliz; também está relacionado a gostar ou não gostar; (ii) Segurança/insegurança: sentimentos relacionados ao bem-estar social - se a pessoa está se sentindo confiante, segura ou desconfiante, ansiosa ou ainda com medo sobre as coisas no mundo, sobre a comunidade ou sobre certas pessoas; (iii) Satisfação/ insatisfação: sentimentos relacionados à conquista ou frustração de uma meta a ser alcançada pelos participantes ou espectadores da ação. Em segundo lugar, o subsistema Julgamento: (i) Estima: envolve admiração ou crítica, que eleva ou rebaixa o indivíduo na estima de sua comunidade, sem implicações legais. Suas unidades de análise são: 'normalidade' (quão incomum alguém é), 'capacidade' (quão capaz ele é) e 'tenacidade' (quão resoluto é); (ii) Sanção social: implica louvor e condenação, mas com base em regras e códigos legais (normas e padrões), estabelecidos por instituições sociais por meio de leis, preceitos morais e religiosos que regem os grupos. Suas unidades 
de análise são: 'veracidade' (quão verdadeiro/honesto é alguém) e 'propriedade' (quão ético alguém é). E por fim, para o subsistema de Apreciação: (i) Reação: as reações que as coisas provocam nas pessoas e como elas chamam nossa atenção (Chamam nossa atenção? Corresponde às expectativas? É bem recebido? Mexe conosco?); (ii) Composição: sentimentos que dizem respeito à avaliação do equilíbrio e complexidade do objeto avaliado (Foi bem elaborado? Foi fácil/difícil de entender?); (iii) Valoração: inovação, autenticidade e relevância do objeto/situação avaliado (quão inovador, autêntico, oportuno é).

Pensando no contexto comunicacional (eleições 2018 no Brasil) e no meio (mídias sociais), o Sistema da Avaliatividade é necessário para verificar as posições de valor determinadas socialmente que os usuários do Facebook, seguidores da página Fato ou Fake, adotam: ou se filiando ou se distanciando da comunidade de interesse associada ao contexto específico (WHITE, 2004). Além disso, é necessário identificar quais são os recursos avaliativos que os escritores utilizam e como os negociam nas relações interpessoais. Vale, por fim, ressaltar que a função avaliativa da linguagem também pode ser realizada por meio dos significados ideacionais (MARTIN e WHITE, 2005), marcados em um texto por "tokens" ideacionais (ALMEIDA, 2010), carregando consigo uma avaliação implícita.

\section{METODOLOGIA}

O Facebook é uma das plataformas mais populares de mídia social. De acordo com Tandoc e colaboradores (2018), ela foi criada inicialmente para conectar pessoas de forma que elas pudessem dividir na rede impressões pessoais com amigos, tendo, posteriormente, se transformado em uma mídia na qual as pessoas produzem, consomem e trocam diferentes tipos de informações, inclusive notícias (TANDOC JR; LIM; LING, 2018). Não é raro que, em um feed de notícias no Facebook, o usuário tenha acesso a informações pela página oficial de uma agência de notícias, veículo noticioso ou pela página de um contato que a tenha compartilhado. O posicionamento dessas notícias em diversos lugares em uma mídia social, muitas vezes, pode distanciar a fonte da informação, assim como seu meio de veiculação. Nesse contexto, o compartilhamento de uma notícia por uma fonte próxima, um amigo ou figura de autoridade embasa a veracidade de uma notícia e facilita a sua propagação na rede. À vista disso, o compartilhamento também favorece o engajamento dos leitores (em forma de curtidas, comentários ou novos compartilhamentos), um ciclo que promove ainda mais a sua propagação (THORSON, 2008). Tudo isso sem que, necessariamente, exista uma sistemática verificação da veracidade da notícia. 
Nesse panorama, a existência de agências verificadoras (fact checking agencies) se justifica pela possibilidade de aplicação de métodos eficazes ${ }^{3}$ para a verificação de um conjunto de informações amplamente divulgadas nas diversas redes. Apesar de agirem de forma mais lenta do que a produção de notícias falsas (KHRIYENKO, 2018) per se, tais agências cumprem um importante papel na verificação e validação (ou não) de textos, sites e imagens que circulam supostamente como "notícias" (PALACIOS, 2019), mantendo o ideal jornalístico de trazer a verdade, o fato, aos seus leitores.

De acordo com o $\mathrm{G} 1(2018)^{4}$, diversos especialistas manifestaram-se a favor do combate à disseminação de conteúdos falsos, pois estes prejudicam a tomada de decisões e colocam em risco a democracia. A fim de impedir a difusão de rumores, os discursos de políticos também passaram a ser checados, confrontando as versões dadas por eles, em entrevistas ou debates, com fontes oficiais. Por se tratar de um ano eleitoral no Brasil (2018) e tendo em vista que o uso de fake news (KHRIYENKO, 2018) foi constatado em processos democráticos de escolha, como nos Estados Unidos, no Reino Unido, na França, na Alemanha e no México, tais checagens e esclarecimentos tornaram-se cada vez mais necessários. No entanto, será que as pessoas acreditam nessas checagens ou preferem acreditar naquilo que alimenta suas crenças? Essa pergunta instigou o interesse pela análise dos comentários que compõem esta pesquisa.

Para este artigo, escolhemos a página da agência de checagem Fato ou Fake, disponível no Facebook. A agência é uma iniciativa do grupo Globo e a apuração é feita em conjunto pelo G1, O Globo, Extra, Época, Valor, CBN, GloboNews e TV Globo. Ela foi criada em 2018 e atualmente, conta com mais de 129 mil seguidores e mais de 1.150 checagens realizadas. Sua finalidade é publicizar as checagens de conteúdos suspeitos mais compartilhados nas mídias sociais, incluindo WhatsApp. A análise de um conteúdo suspeito, ou da fala de algum político, baseia-se na transparência de informações, pautando-se em três pilares: checagem das fontes citadas, metodologia utilizada e correções realizadas após a postagem. Depois, o conteúdo analisado é publicado juntamente com a apuração e pode receber três selos: (i) "fato", quando a mensagem é verdadeira; (ii) "fake", quando a mensagem traz informações incorretas, falsas e sem comprovação; e "não é bem assim", quando há alguma distorção dos fatos. Dessa página, Fato ou Fake, foram coletados 851 comentários sobre 15 postagens feitas entre os dias 17 e 18 de outubro de 2018. O quadro 1 traz as cinco grandes temáticas, nas quais as postagens coletadas foram agrupadas.

3 Normalmente, as agências seguem o seguinte protocolo: pesquisa na internet sobre a postagem original; consulta a fontes oficiais, contextualização, cruzamento de declarações com dados, entrevista com pessoas citadas, testemunhas e/ou especialistas, direito de resposta (DOS SANTOS CARVALHO; DE BRITO SAMPAIO, 2020; G1, 2018).

4 G1 lança Fato ou Fake, novo serviço de checagem de conteúdos suspeitos. Disponível em: <goo.gl/VyULdy>. Acesso em: 10 out, 2019. 


\begin{tabular}{|l|l|}
\hline 1. & Verificação das falas dos candidatos aos governos estaduais em entrevistas e debates \\
\hline 2. & Verificação de cartaz digital \\
\hline 3. & Verificação de áudios e vídeos (edições e recontextualizações) \\
\hline 4. & Verificação da relação imagem/legenda \\
\hline 5. & Verificação de mensagens com grande circulação no WhatsApp \\
\hline
\end{tabular}

Quadro 1. Temáticas das postagens coletadas.

Como podemos observar no quadro 1, há várias temáticas analisadas, mas todas estão relacionadas à política. Na temática $\mathrm{n}^{\circ} 1$, estão as entrevistas com os candidatos aos governos estaduais do Rio de Janeiro, de São Paulo e do Distrito Federal. Dentro da temática $n^{\circ} 2$, um cartaz de promoção de supermercado relacionado ao uso de camiseta de candidato. A temática $\mathrm{n}^{\circ} 3$ é a que contém mais postagens: há diversos vídeos (editados ou recontextualizados) com intuito de difamar ou enaltecer um candidato, além de outros sobre fraudes nas urnas. A temática $n^{\circ} 4$ traz uma foto da época da Ditadura Militar com uma nova legenda a fim de desmoralizar um ex-presidente e seu partido. Na temática $n^{\circ} 5$ temse a especulação a respeito do atentado que um candidato sofreu e uma recontextualização de um livro escrito por um dos candidatos à presidência da república. O corpus coletado é composto pelos itens descritos na Tabela 1:

\begin{tabular}{|l|c|}
\cline { 2 - 2 } \multicolumn{1}{c|}{} & Valores \\
\hline Postagens & 15 \\
\hline Comentários & 851 \\
\hline Tokens & 14119 \\
\hline Types & 2955 \\
\hline TTRatio & 0,20 \\
\hline Tokens/comentários & 16,6 \\
\hline
\end{tabular}

Tabela 1. Descrição do Corpus.

Os dados foram coletados utilizando um software de raspagem de dados do Facebook, chamado Netvizz (ROGERS, s.d.), capaz de coletar dados de páginas, grupos e perfis disponíveis no Facebook em modo público. Para esta pesquisa, foram coletados o conjunto de postagens e seus textos, além de todos os comentários referentes a cada postagem, contabilizando 14.119 tokens (ocorrências) e 2.955 types (palavras), sendo que, no total, foram analisados 851 comentários, com uma média de 16,6 palavras cada.

O processo de tratamento e análise dos comentários seguiu o fluxograma representado na figura 1. 


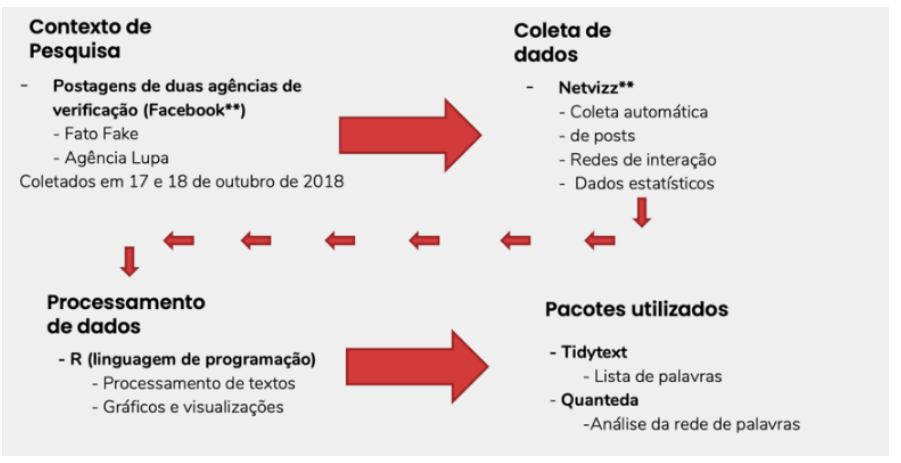

Figura 1. Algoritmo de análise de dados.

A figura 1 resume o processo de tratamento e análise dos comentários. Inicialmente, estabeleceu-se a postagem da agência de pesquisa no Facebook como contexto geral de pesquisa. Apesar de este artigo trabalhar apenas com parte do corpus, a pesquisa inicial contou com o mapeamento de duas agências. O próximo passo foi alimentar o programa Netvizz com os dados específicos da postagem, como número de identificação da página e data da postagem para coleta. O programa, então disponibiliza os insumos necessários para a pesquisa: um arquivo com os comentários e suas datas, métricas de reação à postagem, métricas de acesso entre outras. $O$ arquivo com o texto foi processado através de um script escrito em linguagem de computador R, um programa de análise estatística que também permite a manipulação de strings de texto. Esse processamento visa a limpar os dados de possíveis interferências, códigos no formato HTML/XML que possam ter sito adicionadas no texto, excluindo informações como cabeçalhos e marcações inoportunas. O R também foi utilizado para processamento de texto, o que incluiu a análise de colocados e concordâncias.

Colocados podem ser definidos como uma lista de palavras múltiplas pesquisadas a partir de uma palavra nódulo (LIMA-LOPES, 2016). A função desta lista é observar quais são os itens lexicais que estão mais frequentemente ao lado do termo que se está pesquisando, de forma a se estabelecer unidades linguísticas formulaicas e recorrentes (BREZINA; MCENERY; WATTAM, 2015; GABLASOVA; BREZINA; MCENERY, 2017). Tais estruturas, ou fraseologias, são importantes para que possamos compreender como uma palavra se relaciona funcionalmente e semanticamente com aquelas que estão a sua volta. Pressupõe-se, assim, que diferenças nas colocações possam definir o significado de uma palavra em seu contexto de uso (SINCLAIR, 1991). Podem-se estudar colocados tanto à direita como à esquerda de nossa palavra nódulo, sendo também possível determinar quantas palavras em cada direção o software levará em conta.

A determinação da palavra nódulo e do universo de pesquisa (palavras à direita ou à esquerda) são definidas pelo pesquisador e seu interesse analítico, ao passo que a relevância dessas colocações é determinada estatisticamente (GABLASOVA; BREZINA; 
MCENERY, 2017)5. Esta relação subjetiva, escolha a partir de interesses de pesquisa contextualmente motivados, e a aplicação de métricas para observância dos resultados é o que motiva Biber et al (1998) a definir a linguística do corpus como uma abordagem tanto qualitativa como quantitativa.

De acordo com Sinclair (1991), uma concordância poderia ser definida como uma coleção de ocorrências de um item lexical, em seu contexto textual específico, uma lista de exemplos no qual a palavra pesquisada (nódulo) estaria na posição central, dividindo seu contexto linguístico imediato a direita ou a esquerda. 0 quadro 2, a seguir, traz um exemplo desta ferramenta.

\begin{tabular}{|c|l|l|l|l|}
\hline text1 & 53 & fala serio pq aqui so tem fake do & haddad & ?? pq sera ? ? com tantas fakes news \\
\hline text1 & 182 & kkkk claro que e fake! mesmo se o & haddad & $\begin{array}{l}\text { ganhasse, o exercito nao serviria para se- } \\
\text { guir ordens deles }\end{array}$ \\
\hline text1 & 258 & mas agora depois de ouvir tudo o que o & haddad & falou, mudei meu voto ! agora dia 28 \\
\hline text1 & 682 & $\begin{array}{l}\text { parte do que voce mencionou a res- } \\
\text { peito do }\end{array}$ & haddad & $\begin{array}{l}\text { sao fakes sim ! deve-se questionar quem as } \\
\text { enviou ! }\end{array}$ \\
\hline text1 & 845 & o numero de fake news contra o pt e o & haddad & sao maiores e mais bem divulgadas. sabe o que \\
\hline
\end{tabular}

Quadro 2. Exemplo de concordância.

A concordância é ainda uma das principais ferramentas de análise em linguística do Corpus, uma vez que, quando lida verticalmente, também ajuda a observar padrões de uso e, portanto, significados (TRIBBLE, 2010). No caso deste estudo, as concordâncias serviram ao propósito de observar o contexto expandido das conclusões observadas nos colocados. Por uma questão de espaço, este artigo estudou os 25 colocados mais relevantes de cada candidato e suas respectivas concordâncias.

Todos os dados foram processados usando dois pacotes principais para análise de texto6. O pacote Quanteda foi responsável pelas concordâncias, por obter estatísticas gerais do corpus (tais como número de tipos e formas) e pela representação da rede de colocados (BENOIT et al., 2018); já o pacote TidyText possibilitou a organização dos dados e o cálculo da significância das palavras e colocados (SILGE; ROBINSON, 2017).

\section{RESULTADOS}

Inicialmente, realizou-se uma análise lexical exploratória dos comentários, de forma a observar quais seriam as entidades mais comumente avaliadas dentro do contexto dos

5 Apesar da relevância da discussão sobre os cálculos estatísticos para os colocados, ela estaria muito além do escopo deste trabalho. Sugerimos ao leitor a reflexão de Gablasova et al. (2017) como ponto de partida para uma reflexão mais aprofundada.

6 Os scripts para análise de dados estarão disponíveis em: http://www.iel.unicamp.br/rll307 e

https://github.com/rll307/ArtigoFatoFake 
comentários levantados. A figura 2 traz uma rede de colocados, na qual foram levadas em conta as 50 palavras mais comuns no corpus. Os resultados mostram que os dois candidatos ao segundo turno nas eleições presidenciais - Fernando Haddad e Jair Bolsonaro - ocupam um lugar central, levando-os a ser o ponto fundamental nas discussões que ali ocorrem. Ambos se conectam por meio de diversos colocados, como é o caso das palavras fake, folha, ladrão e gay.

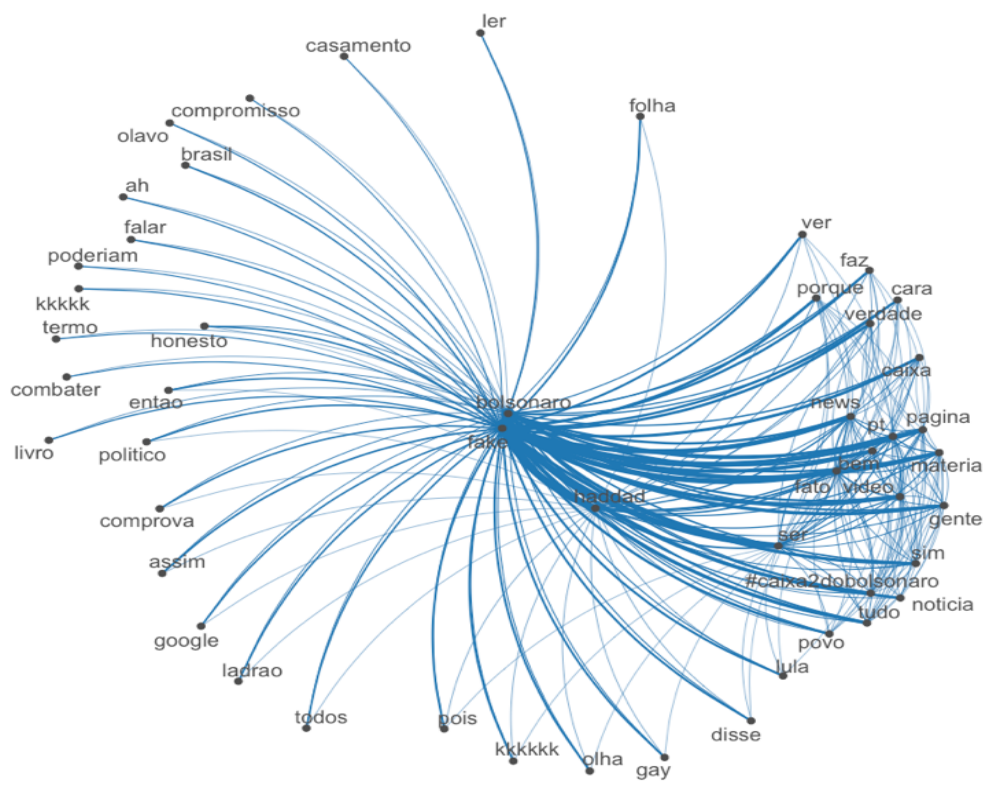

Figura 2. Rede de colocados nos comentários.

Todavia, apesar de ambos os candidatos possuírem uma posição de destaque, observamos que Bolsonaro está mais ao centro da rede. Isso pode significar que ele representa o item lexical mais relevante dentre esta amostra de 50 palavras, comportamento que tende a se manter caso a rede seja ampliada.

Uma observação mais atenta também nos mostra que, apesar de Fernando Haddad e Jair Bolsonaro estarem próximos em termos topológicos na representação trazida pela figura 2, ambos parecem conectados às mesmas palavras. Tais resultados podem indicar que as temáticas as quais Haddad se relaciona também estão relacionadas a Bolsonaro, entretanto este parece ser mais central e importante para elas que aquele. Uma vez que o primeiro candidato se coloca mais periférico que o segundo, é aceitável concluir que Haddad é colocado de Bolsonaro e não vice-versa.

Outra questão que chama a atenção é o fato de as palavras que estão à direita da rede formarem uma rede mais densa do que aquelas que estão à esquerda. Isso porque as da direita parecem estar diretamente ligadas aos candidatos, ao passo que as da esquerda 
coocorrem como colocados entre si. Analisemos alguns casos relacionados aos colocados mais frequentes e suas diferentes funções avaliativas.

Em alguns casos, essas palavras parecem ocorrer como qualificadores que julgam a questão ética dos candidatos, como é o caso de ladrão (ex. 1) e de honesto (ex. 3 e ex. 4). Não raro, algumas entidades relacionadas aos candidatos estão presentes, como é o caso do ex-presidente Luís Inácio Lula da Silva (ex. 2) e de Olavo de Carvalho (ex. 5).

Ex1. Preciso concordar tudo que sai na mídia sobre ele é verdade. Corrupto, ladrão, mais de 30 processos, pior prefeito de São Paulo. e por aí vai.

Ex2. O homem mais honesto do planeta é o luladrão! Eita povo esquecido! bolsonaro $17 \mathrm{com}$ tudo pra cima desses degenerados.

Ex3. So um doido pra definir um politico como mais honesto do mundo principalmente sendo do brasil. agora mais do que Haddad com certeza ele [Bolsonaro] é!

Ex4. Fato é que Bolsonaro é o mais honesto disparado (...)

Ex5. Essa matéria é tendenciosa e tem como objetivo desacreditar o professor Olavo.

Ao analisarmos a rede formada pelo candidato Jair Bolsonaro, observamos que, entre as palavras que possuem maior conexão, estão: caixa, matéria, página, o jornal Folha de São Paulo, político e gay. Em alguns casos, essas colocações refletem uma avaliação positiva indireta do candidato em termos de suas ações, especialmente em termos morais (ex. 6), uma vez que a prosódia semântica ${ }^{7}$ da proposição seria positiva pela perspectiva conservadora de seus eleitores. Em outros casos, Bolsonaro também é caracterizado positivamente tendo em vista a proposição que uma crítica a ele dirigida, proferida por Haddad (segundo o autor da postagem), e publicada pela imprensa não foi checada pela agência (ex. 7). Aqui há um julgamento de sanção implícito que recai sobre três entidades. Bolsonaro é avaliado positivamente por ser representado como vítima ao passo que seu concorrente político e o jornal sofrem uma avaliação negativa (ex. 8).

Ex6. Bolsonaro assina termo de compromisso para combater casamento gay (...)

Ex7. A folha nao faz checagem de fato da acusacao de haddad de que a materia do jornal " comprova que bolsonaro criou uma organizacao criminosa "?

7 Em linguística do corpus, o termo "prosódia semântica" se refere ao acúmulo de escolhas lexicogramaticais que levam a uma percepção positiva, negativa ou neutra de um texto. O texto, desta forma, pode ser caracterizado por ondas de escolhas lexicais significativas ancoradas em padrões colocacionais que determinam sua prosódia (BEDNAREK, 2008; HUNSTON, 2007; MARTIN, 2008). 
Ex8. Politico nao tem santo. e a fake news dizendo que o bolsonaro votou contra lei de inclusao de pessoas com deficiencia?

A relação de Bolsonaro com a palavra "político" (ex. 8) parece trazer uma relação de compensação de conduta em sua avaliação. Por um lado, ele é negativamente avaliado pela negação do adjetivo "santo", negatividade que é compensada pela atribuição de uma notícia falsa sobre uma votação no congresso. O mesmo ocorre ao se atribuir falsidade à ideia de que Bolsonaro seria corrupto (ex. 9).

Caixa, que também tem uma coocorrência alta com a palavra Bolsonaro, está relacionada a uma denúncia de caixa 2 realizada contra o candidato às vésperas da eleição (ex. 10). Nos exemplos a ela relacionados, há apenas tentativas de invalidar a denúncia, seja pela utilização de hashtags, seja pela ridicularização da denúncia, que se dá, em alguns casos, pelo tom irônico da pergunta e pela afirmação que tal ação gratuita é feita pelo autor da postagem em benefício do candidato. Nesse caso, o modo tem especial papel na avaliação, uma vez que o tom gerado pela pergunta é o elemento responsável pelo efeito que traz (ex. 11).

Ex9. kkkkk bolsonaro ladrao isso sim é fake kkkkkkk kkkkkkkkk

Ex10. caixa 2 para pagar campanha no whatsapp? mas eu faço campanha de graça pro Bolsonaro!

Ex11. \#haddad13 acham que podem manipular o povo com essa página que só distorce as coisas??! \#bolsonaro17

A rede de Fernando Haddad é diferente. O candidato está ligado a menos palavras, que tendem a se conectar mais entre si e que possuem linhas de relação mais espessas, indicando uma forte coocorrência dentro do mesmo comentário. Como é possível observar, seus colocados parecem interagir mais frequentemente entre si, criando uma rede discursiva bem mais complexa do que a de Jair Bolsonaro. Fernando Haddad também se distancia da palavra fake que, por estar adjacente a Bolsonaro, é um indicativo topográfico de seu uso mais constante acompanhando tal candidato (ex. 25) .

Um ponto a ser levado em consideração é que, apesar das diferenças topográficas, parece haver uma certa semelhança entre as palavras que o nome de Fernando Haddad se conecta, de certa forma, elas parecem ser um subconjunto daquelas relacionadas a Bolsonaro.

8 Ex 25. Melhor que o haddad ele é com certeza-esse exemplo será analisado com mais detalhes posteriormente. 
Algo que chama a atenção, entretanto, é a natureza das conexões, uma vez que o candidato está ligado a palavras como sim, ser, \#caixa2dobolsonaro e bem por meio de linhas mais espessas do que com os demais termos. Vejamos alguns exemplos dessas ocorrências mais frequentes:

Ex12. \#haddad13 fato e que Bolsonaro e o mais honesto disparado se não foi, deveria ser esse cara não cansa de passar vergonha.

Ex13. \#bolsonacaixa2 mais e um dos poucos honestos as fake do Haddad a Globo não mostra (...)

Como é possível observar no exemplo 12, a representação de Fernando Haddad parece ser definida em termos de sua oposição a Bolsonaro. Haddad é tido como beneficiário de uma ação negativa realizada por um canal televisivo (ex. 13), além de ser classificado como menos honesto em comparação a Bolsonaro. Outro ponto importante trazido pelo exemplo 13 é uma espécie de normalização das notícias falsas. Ali, parece-se marcar a prática de desinformação como algo pretensamente normal, uma estratégia de campanha realizada por todos os candidatos. Se por um lado, isso implicaria que a emissora de televisão beneficiaria Haddad por esconder aquelas pelas quais o candidato seria responsável, por outro assume a existência de tal prática pelos apoiadores do outro candidato ${ }^{9}$. Já no exemplo 14, Haddad é avaliado por um idiomatismo: "tapar as nuvens negras do Haddad com uma peneira", cuja principal função é inserir um juízo de valor negativo, talvez para questionar a neutralidade da agência verificadora. Nesse sentido, Haddad, assim como os meios de comunicação que tecem críticas a Jair Bolsonaro, sofrem julgamento de sanção em termos de sua propriedade e veracidade. Todavia, tal julgamento se dá de maneira inversa a de Bolsonaro. Aquele representa os valores negativos que são utilizados em contraponto a forma positiva com a qual este é caracterizado.

O fato de esses candidatos serem o centro da discussão frustrou nossas expectativas iniciais. Isso porque imaginávamos que, em uma postagem cujo objetivo seria discutir a veracidade ou não de notícias divulgadas na internet, as postagens devessem discutir o papel da agência, seus métodos de verificação ou mesmo a notícia em si. De maneira geral, existem poucas citações à agência (ex. 15 a 17), sendo todas elas negativas e quase nenhuma citando partes das matérias analisadas ou os dados levantados por ela. Tal avaliação está relacionada principalmente aos julgamentos em termos da propriedade da verificação das notícias. Inicialmente, a agência é julgada como não confiável, seja por estar associada a um dos candidatos à presidência ou por escolher fatos para análise que, em tese, o 
beneficiaram (ex. 16). Alguns dos exemplos a seguir podem nos auxiliar a elucidar como esses comentários se constroem em uma narrativa que descredencia a agência averiguadora.

Ex14. mas nao e fake. vcs poderiam escrever " nao e bem assim " e explicar ao inves de tapar as nuvens negras do haddad com uma peneira.

Ex15. fato ou fake e muito mais fake do que fato.

Ex16. nem vou perder mais o meu tempo pra ler essa de fato ou fake. voces sempre dando um jeitinho de safaro haddad (...)

Ex17. fake e essa pagina (-); ;) fato ou fake e muito mais fake do que fato (...)

Ex18. Acham que podem manipular o povo com essa página que só distorce as coisas??! \#bolsonaro17

Há, assim, críticas (Apreciação - Reação Negativa) à página Fato ou Fake, questionando principalmente a ética (Julgamento de Propriedade) e o quão estava preocupada com a verdade (Julgamento de Veracidade), sobretudo proferidas pelos apoiadores de Bolsonaro (ex. 14 e 18). Além desse impacto negativo que algumas postagens causaram em alguns seguidores da página, houve também atitudes apreciativas quanto à qualidade da informação trazida (ex. 14 e 18). Na maioria das proposições, tal julgamento ocorre sem que haja justificativas claras (ex. 18), sendo realizado com o objetivo de minar a credibilidade da agência. Comportamento este também relacionado aos veículos jornalísticos, algo que vem se tornando cada vez mais comum (TANDOC JR; LIM; LING, 2018).

Dada a centralidade dos candidatos nas discussões promovidas pelos comentários, uma análise dos colocados de cada um deles foi realizada (figura 3). Esta análise comparativa tem por objetivo observar como cada um dos candidatos é caracterizado a partir de uma análise individual - isolando-se os colocados de cada um - e comparativa - na qual tais individualidades são contrastadas. A figura 3 traz os colocados dos dois candidatos, sendo que 3-A representa os colocados de Jair Bolsonaro e 3-B os de Fernando Haddad. 

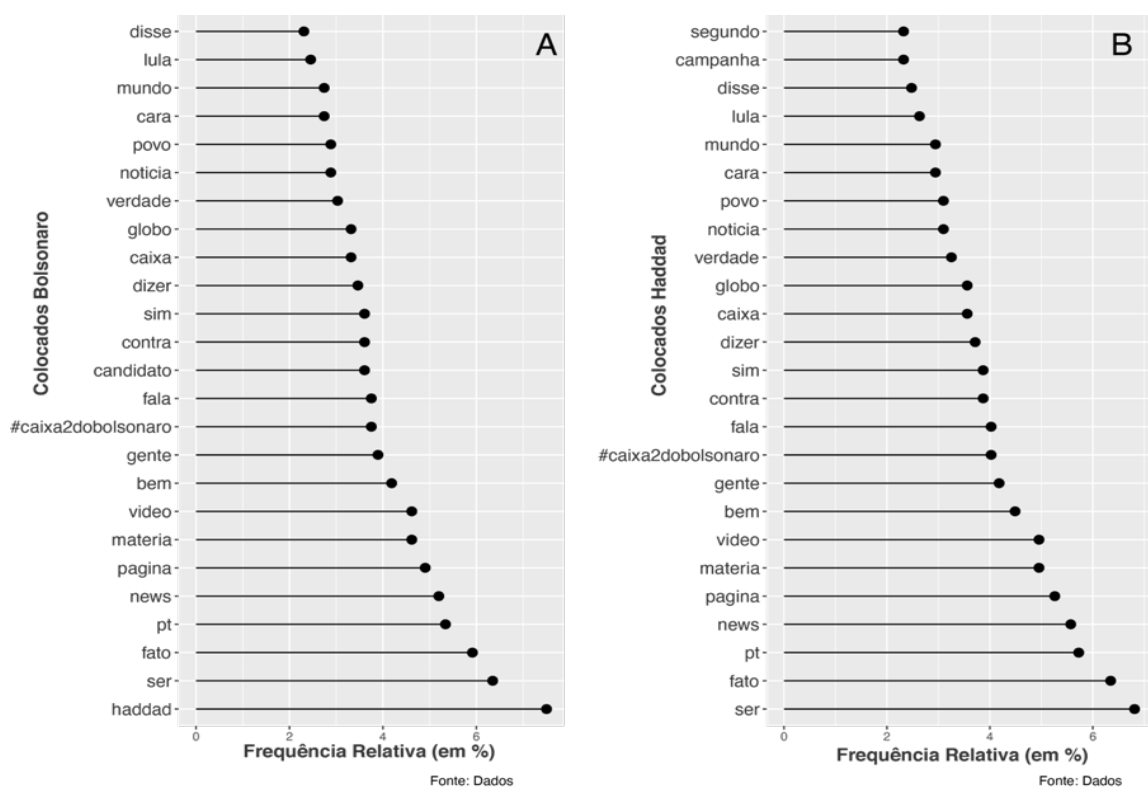

Figura 3. Colocados de Jair Bolsonaro e Fernando Haddad em comparação.

Algo que nos chamou a atenção foi o fato de Fernando Haddad e a sigla do Partido dos Trabalhadores (PT), além de referências ao ex-presidente Lula, estarem entre os colocados mais frequentes na lista de Bolsonaro. Se compararmos com a lista de Haddad (figura 3B), observaremos que Bolsonaro não aparece diretamente; ele está ali representado por uma hashtag, que também está presente na lista representada pela figura 3-A. As referências ao Partido dos Trabalhadores e a Lula também aparecem como parte dos colocados de Haddad, algo que estaria dentro do esperado.

No que tange as demais palavras, elas parecem ser muito semelhantes, com referência a matérias de jornal (ex. 19), emissoras de televisão (ex. 13), proposições que demonstram o alvo das ações discursivas (ex. 20), além de referência a uma hashtag (ex. 21). Atentaremos mais detalhadamente a esses usos, por se relacionarem a imprensa e consequentemente terem uma relação indireta com a agência foco de nossa pesquisa. De maneira geral, tais proposições buscam construir um julgamento indireto, que está relacionado à veracidade e propriedade de ações realizadas por pessoas e meios de comunicação que têm o candidato como opositor, sendo que ele, por conseguinte, é julgado positivamente em termos de sua conduta. Parece que uma equação é construída em termos de argumentação: atribui-se uma polaridade positiva como resultado de uma ação avaliada como negativa ou imprópria.

Ex19. вR a fake so a data do haddad tudooo é fake :-8) (a) conta outra!

Ex20. haddad tem 3 investigacoes do mp e vcs tem contra o bozo uma materia do folha de sao Paulo (...) 
Ex21. \#caixa2dobolsonaro por que a folha nao faz checagem de fato da acusacao de haddad de que a matéria do jornal (...)

Pela análise apresentada nos exemplos mencionados acima, percebe-se que , Jair Bolsonaro é avaliado com base em sua diferença com relação à Fernando Haddad, à medida que este é classificado como favorecido pela mídia e de reputação menos ilibada que aquele, uma natural e implícita avaliação positiva recai sobre Bolsonaro (ex. 20 e 21). Nesses casos há um julgamento em termos de sanção, criticando a postura ética de tais meios de comunicação, ao mesmo tempo que Haddad e Bolsonaro sofrem sanções de propriedade consequentes de tal avaliação: o primeiro negativo, o segundo positivo. No caso do exemplo 19, há uma negação indireta, utilizando-se uma expressão modal de indignação ("conta outra!"), ao passo que no exemplo 21, Bolsonaro é classificado como honesto - algo que é intensificado pelo julgamento ético negativo de uma emissora de televisão - sendo objeto de uma negação direta. Ainda no exemplo 20, é interessante analisar que a quantidade de processos atribuídos a um dos candidatos busca dirimir a possível não checagem dos fatos por um jornal paulista.Tal estratégia explicaria, em termos discursivos, não apenas as semelhanças apresentadas pelas figuras 3-A e 3-B, mas também porque os candidatos não coocorrem mutuamente em suas listas. Em termos gerais, tais resultados parecem refletir um modelo de argumentação chamado em lógica de prova por contradição ou reductio ad absurdum. Nesse modelo (HARDY, 1940), uma proposição tende a ser provada mostrandose um cenário contraditório em relação a suas características essenciais, sem, contudo, defini-las. Essa estratégia de se estabelecer um eixo sintagmático amigo-inimigo, julgando negativamente o outro para se fortalecer, também foi observada no trabalho de Mercuri e Lima-Lopes (2020), em que comentários no Twitter sobre a greve geral em 2017, configuraram uma polarização política que, como podemos observar neste artigo, permaneceu no ano seguinte (em 2018).

Em nosso corpus, nota-se que essa estratégia permite que a honestidade de um candidato seja determinada pela sua oposição ao comportamento de seu adversário ou a maneira como ele é tratado pela mídia. Uma interpretação possível desse resultado é que, ao estar como elemento central, Jair Bolsonaro também parece estar colocado como elemento mais determinante das relações discursivas que são estabelecidas ao redor de seu nome, uma vez que todas as palavras, se relacionam a ele. Talvez isso possa justificar uma observada ação maior por parte dos apoiadores do candidato Bolsonaro, pois foram encontradas 69 expressões de Afeto ou Julgamento positivas, ao passo que o candidato Haddad obteve apenas 10. Outro fato curioso é que em 26 comentários, para exaltar Bolsonaro, foi feita uma avaliação negativa de Haddad (ex. 22), sobretudo com julgamentos de propriedade ligados, na maioria das vezes, à corrupção. Esse tipo de julgamento sobre Haddad está diretamente ligado ao julgamento de seu partido, o PT. Nesses casos, a avaliação do 
candidato Fernando Haddad é instanciada pela associação do candidato com adjetivos e substantivos de teor negativo, entre eles estariam bandidos, comunistas e quadrilha terrorista (ex. 22).

Ex22. haddad e td o PT bandidos quadrilha terrorista, comunistas malditos: \#bolsonaro17 \#OlavoTemRazão \#PTNuncaMais

O Julgamento de Propriedade também foi o mais representativo nos comentários analisados, quando foi considerada a palavra Haddad desvinculada da palavra Bolsonaro (ex. 23). Apesar de não ser o foco principal deste trabalho, é importante observar que algumas relações de posse (ex. 23) também são utilizadas com valor avaliativo. Ao associar o candidato a processos no Ministério Público, é possível observar um julgamento negativo em termos de propriedade, mesmo que tais processos ainda não tenham sido julgados.

Ex23. olha a quantidade de processos que o haddad tem pelo MP olha ai no google triste ver a que ponto chega a pessoa pra endeusar politico

Em análise das ocorrências para o candidato Bolsonaro, a que mais se destaca foi de Afeto de felicidade, ou seja, da ordem do gostar (ex. 24 e 25) e, como é comum nesse tipo de sentimento, parece não se estabelecer um processo argumentativo que justifique a relação de afeto, como pode-se perceber nos exemplos abaixo:

Ex24. Vcs querendo ou não, ele será nosso presidente! \#aceitaquedoimenos \#bolsonaropresidente \#B17

Ex25. Melhor que o haddad ele é com certeza

Além disso, tais avaliações parecem também servir para exprimir processos de engajamento e afastamento. Entre as estratégias estão os pronomes a gente e nosso utilizados de forma a indicar a filiação a um grupo de apoiadores. Esse uso visa a criar subgrupos dentro da discussão motivada pelos comentários e buscam reproduzir um efeito de polarização similar ao que se estabelece no contexto avaliativo.

As hashtags são utilizadas como elementos indexadores, por vezes gramaticalizados, da discussão e do engajamento discursivo (LIMA-LOPES; PIMENTA, 2017; LIMA-LOPES, 2019). Durante a análise, foi possível observar a existência de uma relação entre sua presença no texto e a polaridade do comentário: comentários que avaliavam positivamente o candidato Jair Bolsonaro possuíam em seu corpo um conjunto de hashtags que marcavam essa avaliação positiva, ao mesmo tempo que também assinalavam críticas em relação ao 
candidato Fernando Haddad. Naturalmente, as poucas instâncias de avaliação positivas deste último também estão ligadas a hashtags específicas. Um resumo das relações por elas estabelecidas está presente na figura 4.

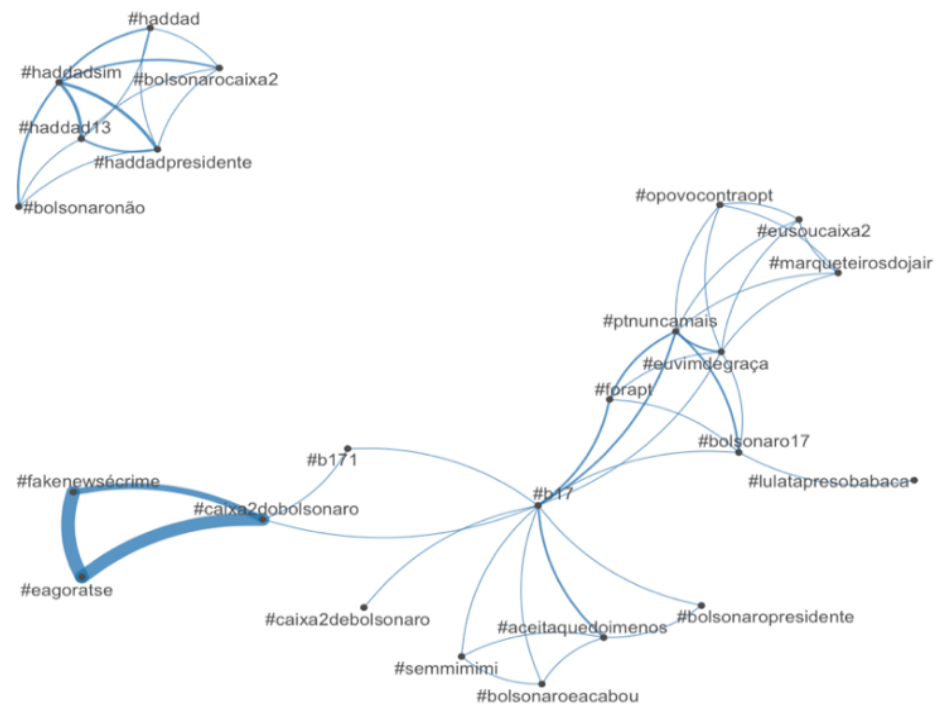

Figura 4. Relação entre as 30 hashtags mais frequentes.

Podemos observar dois grupos bem definidos. No primeiro, expressões como \#bolsonaropresidente, \#b17 e \#bolsonaro17 marcam a filiação e, portanto, a inclusão no grupo de apoiadores de Jair Bolsonaro, ao passo que \#haddadpresidente, \#haddad e \#haddadsim marcam o apoio a Fernando Haddad. As linhas mais espessas entre \#eagoratse, \#fakenewsécrime e \#caixa2dobolsonaro indicam uma forte relação de coocorrência entre elas, como nos seguintes casos:

Ex26. Vcs querendo ou não, ele será nosso presidente! \#aceitaquedoimenos \#bolsonaropresidente \#B17

Ex27. Meu Deus, como está lindo ver o desespero dessa corja suja!! \#eusoucaixa2 \#marqueteirosdojair \#opovocontraoPT \#PTnuncamais \#euvimdegraça

Há outros casos como \#aceitaquedoimenos, \#ptnuncamais, \#bolsonaro e \#forapt (ex. 26 e 27) que parecem ter um efeito bastante similar à estratégia de afastamento e de questionamento da propriedade e veracidade. Outras hashtags como \#euvimdegraça e \#eusoucaixa2 (ex. 27) marcam ainda um terceiro tipo: engajamento. Elas são respostas diretas a algumas críticas realizadas pelos meios de comunicação contra um dos candidatos, algo que faz com que os autores dos comentários se alinhem não apenas ao candidato, mas também às críticas que são tecidas aos meios de comunicação. 
Um ponto importante a ser observado nesses resultados é que a estratégia utilizada pelos que se filiam ao então candidato Jair Bolsonaro constrói o caráter positivo do seu candidato por meio das críticas tecidas a seu adversário (ex. 30, 31 e 32), o que parece não ocorrer nas hashtags ligadas a Fernando Haddad (ex. 28 e 29 e 31). Na verdade, elas parecem estar presentes em postagens que demonstram um acúmulo de hashtags positivas, em um efeito de intensificação. Os apoiadores de Fernando Haddad utilizam hashtags como \#bolsonaroRacista e \#bolsonaroHomofóbico levando a uma avaliação positiva do candidato, algo que parece ocorrer de forma implícita. Nesse sentido, há também a utilização da prova por contradição ou reductio ad absurdum (HARDY, 1940), todavia, tais apoiadores utilizam apenas as hashtags para tal propósito.

Ex28. \#haddadPresidente13 \#haddadBrasil \#SomosTodoshaddad \#Votohaddad \#OBrasilFelizDeNovo \#haddadSim \#ViolênciaNão \#AgoraÉhaddad \#VivaADemocracia \#haddad2018 \#EleSimhaddad13 \#haddadSim \#haddadEstadodedireito

Ex29. \#bolsonaroNão \#bolsonaroNunca \#haddadSim \#haddademocracia \#haddadLiberdade \#bolsonaroRacista \#bolsonaroHomofóbico \#bolsonaroMachista \#bolsonaroRetrocesso

Ex30. Vai acabar a mordomia cambada de vagabundo! \#B17 \#aceitaquedoimenos \#semmimimi \#bolsonaroeacabou

Ex31. Já o Cara do caixa 2 de vocês é péssimo. Tanto é, que tá preso. \#OlulaTáPresoBabaca

Ex32. \#ptnuncamais \#PTNAO \#FORAPT \#B17 \#17neles \#chupaG1

As hashtags ainda estão relacionadas à avaliação desses candidatos em termos de julgamento de sanções, de apreciação e intensificação. No caso da primeira, observa-se que algumas hashtags compõem ações discursivas e avaliativas complexas e sendo instanciadas por orações cujos elementos essenciais estão presentes, tais como \#AgoraÉhaddad (ex. 28) e \#OlulaTáPresoBabaca (ex. 31). Esse tipo de processo não apenas cria um idiomatismo, que pode ser interpretado como um sinal de engajamento, como também cria uma estrutura gramatical avaliativa específica das mídias sociais. Nesse sentido, essas hashtags extrapolam algumas características já observadas em outros estudos (LIMA-LOPES; PIMENTA, 2017; LIMA-LOPES, 2019), que estão relacionadas principalmente à indexação do discurso ou sua presença como um elemento da oração. Aqui, elas funcionam como uma proposição completa, podendo ocorrer de forma independente na postagem (ex. 32).

Na segunda, de apreciação, como mostram os exemplos 29 e 30, as hashtags instanciam significados responsáveis pela apreciação de reação positivas (\#haddadLiberdade e \#bolsonaroeacabou) e negativas (\#bolsonaroRacista, \#bolsonaroRetrocesso). No caso de 
nosso corpus de pesquisa, a estruturação desse processo avaliativo parece seguir padrões específicos para cada candidato. As positivas de Jair Bolsonaro, menos frequentes, seguem uma estrutura similar a uma oração, possuindo alguns termos essenciais e com outros inferiveis pelo contexto, como seria o caso em \#[é]bolsonaroeacabou ou em \#aceitaquedoimenos. Já as positivas relacionadas a Fernando Haddad possuem três padrões. No primeiro, elas seguem a mesma estrutura proposicional com orações de estrutura completa, isto é \#SomosTodoshaddad e \#Votohaddad. Na segunda, elas possuem o nome do candidato seguido por substantivos que ganharam valor positivo no contexto eleitoral de 2018, tais como \#haddadBrasile \#haddadLiberdade.

Em um terceiro padrão, de intensificação, há a presença de hashtags pró-democracia, que são interpretáveis como positivas ao candidato graças à sua colocação. Um exemplo seria a sequência observada no exemplo 28, no qual hashtags como \#ViolênciaNão e \# VivaADemocracia tem ao seu lado outras como \#haddadSim e \#AgoraÉhaddad. Apesar de as duas primeiras não levarem o nome do candidato ou seu partido, sua presença em um ambiente a ele favorável faz com que seu nome seja positivamente associado a elas. Aqui também há uma estratégia de avaliação positiva indireta por meio da justaposição.

As hashtags negativas seguem uma estrutura diferente das positivas para cada um dos candidatos. No caso de Jair Bolsonaro, elas parecem estar relacionadas a justaposição do nome do candidato a advérbios ou adjetivos negativos (exemplo 29). Outrossim, haja avaliações negativas associadas a Fernando Haddad, seu padrão é diferente. Não há a menção direta ao seu nome em tais hashtags, uma vez que elas são estruturadas de forma a trazer agressões a seu partido ou a seus membros históricos (exemplos 31 e 32).

Por fim, a intensificação nas hashtags ocorre de duas formas. A primeira está relacionada à utilização de caixa alta alternada (ou Cameo Letters) de forma a destacar elementos específicos da avaliação. Tais elementos podem estar ligados à identificação de adjetivos, como em \#bolsonaroMachista, advérbios, como em \#bolsonaroNunca e \#haddadSim, substantivos, como em \#haddadLiberdade, ou mesmo para destacar os termos em uma hashtag que traz uma proposição completa, como em \#OlulaTáPresoBabaca. O efeito desse tipo de prática faz com que haja uma relação mista de foco - uma vez que a letra maiúscula ganha destaque - e força - uma vez que ela ganha em intensidade - modulando a atenção do leitor. Esse efeito é diferente da já comumente utilizada caixa alta, como em \#PTNAO, \#FORAPT, que associa a forma e o foco a ação de gritar. A segunda está relacionada ao acúmulo de hashtags avaliativas, que ao serem sequenciadas em uma postagem, criam uma espécie de amontoado semântico (ex. 28, 29 e 32 ). Há um empilhamento de significados que refletem uma determinada postura no contexto representado pelas reações às postagens. Mesmo não havendo um padrão para tal repetição, uma vez que as hashtags parecem variar muito em termos de sua sequência, elas refletem um forte ato de apoio e comprometimento. 


\section{CONSIDERAÇÕES FINAIS}

Este artigo estudou os comentários de uma série de postagens da agência de checagem de notícias Fato ou Fake. Nosso objetivo inicial era compreender como os usuários do Facebook reagiam e interagiam ao discutir as postagens feitas pela agência de verificação de notícias Fato ou Fake nos dias 17 e 18 de outubro de 2018 sobre os resultados da verificação de um conjunto de notícias de grande repercussão nesse período, às vésperas do segundo turno das eleições presidenciais.

Contudo, nos deparamos com o fato de que os comentários não estavam relacionados à verificação realizada e apresentada pelas postagens. O que se apresentou foi o palco de uma série de discussões políticas polarizadas entre os defensores dos dois candidatos do segundo turno das eleições. Não houve, assim, preocupação em discutir qualquer tipo de implicação ou consequência de tal verificação, o que demonstra que o posicionamento apresentado pelas agências de checagem de fatos pouco impacta na versão que os usuários que as comentaram têm de um determinado tema, pois os fatos estão condicionados a posições pessoais pré-existentes. Esse comportamento no qual as convicções pessoais são mais válidas que os fatos, é o que se denomina chamar de mundo "pós-verdade" ou "pós-fato" (KHRIYENKO, 2018). Pautado nesse comportamento, verificase que o compartilhamento e engajamento com as fake news estão mais relacionadas com as emoções despertadas pelo conteúdo apresentado - nossas visões de mundo, preconceitos, ideias e filiações - do que pela preocupação com a checagem de se elas são verdadeiras ou não (DAFONTE-GÓMEZ, 2018). A capacidade de interpretar, entender e avaliar uma informação está intrinsecamente relacionada ao nosso afeto (SLOVIC et al., 2007). Os comentários relacionados a estas checagens e o compartilhamento das postagens analisadas seguem a mesma lógica.

De posse desses resultados iniciais, decidimos que seria importante compreender como essa polarização invadiu tal espaço e como ela se modulou aos interesses de ambos os grupos partidários tendo como norte metodológico a teoria da Avaliatidade. Tal sistema busca refletir sobre como a avaliação é expressa em termos linguísticos por meio de uma rede de escolhas, baseando-se em nossas (enquanto sociedade) crenças, valores, assim como na intenção comunicativa de uma comunidade em um determinado contexto.

Os resultados caminham para uma constante avaliação dos dois candidatos à presidência, assim como da agência de verificação. Tal avaliação se deu principalmente em termos de julgamentos e sanções éticas e morais. Apesar de pouco presente, a avaliação do afeto está na caraterização de um dos candidatos.

Importante observar que algumas estratégias avaliativas estão calcadas não no enaltecimento de qualidades positivas de um candidato, mas sim pelo julgamento negativo de seu opositor. Esse tipo de estratégia, chamada de prova por contradição (HARDY, 1940), 
tem por objetivo caracterizar um candidato positivamente por meio da caracterização negativa do outro. Esse tipo de construção argumentativa tende a trazer pouca, ou às vezes nenhuma, informação sobre aquele que é positivamente avaliado nos comentários.

Uma consequência dessa estratégia pôde ser observada no nível lexical, uma vez que os dois candidatos mostram muita semelhança entre seus colocados mais frequentes. Além disso, Fernando Haddad está entre os itens lexicais mais comuns de Jair Bolsonaro, ao passo que a recíproca não é verdadeira. Quando os partidários de Fernando Haddad utilizam tal estratégia, ela está circunscrita às hashtags.

Neste trabalho, também realizamos um estudo das hashtags e seu uso em termos do engajamento, julgamento e intensificação. Os resultados mostram que seu uso extrapola sua função inicial de indexação para busca em mídias sociais, representando uma série de ações discursivas interessantes e intensificadoras de construção de sentido, uma vez que ao gramaticalizarem-se ou serem usadas de forma contínua formam parte de um discurso fluido e, mesmo que de forma implícita, consistentemente desenhado.

Apesar das limitações do corpus, acreditamos que este trabalho traz algumas contribuições relevantes para a análise do discurso de polarização em mídias sociais, em especial no que tange às estratégias de construção da avaliação no discurso político em contexto de campanha. Todavia, acreditamos que haja a necessidade de discussões não apenas em corpora mais amplos, mas também que estejam relacionados a outras agências de checagem de informações e a outras mídias sociais, de forma a observar se as estratégias aqui identificadas são localizadas ou podem ser generalizadas para novos contextos.

\section{AGRADECIMENTOS}

O presente trabalho foi realizado com apoio da Coordenação de Aperfeiçoamento de Pessoal de Nível Superior - Brasil (CAPES) - Código de Financiamento 001. Rodrigo Esteves de Lima-Lopes agrade ao CNPq (processo 422111/2018-0) pelo financiamento.

\section{REFERÊNCIAS}

ALLCOTT, H.; GENTZKOW, M. Social Media and Fake News in The 2016 Election. Journal of Economic Perspectives, v. 31, n. 2, p. 211-236, 2017.

ALMEIDA, F. A. S. D. P. A avaliação na linguagem: os elementos de atitude no discurso do professor. São Carlos: Pedro \& João Editores, 2010. 
ALMEIDA, F. S. D. P. Atitude: afeto, julgamento e apreciação. In: VIAN JR, O.; DE SOOUZA, A. A.; ALMEIDA, F. S. D. P. (org). A linguagem da avaliação em Língua Portuguesa: estudos sistêmicos-funcionais com base no Sistema de Avaliatividade. São Carlos: Pedro e João Editores, 2011, p. 99-112.

BEDNAREK, M. Semantic preference and semantic prosody re-examined. Corpus Linguistics and Linguistic Theory, v. 4, n. 2, 2008.

BENOIT, K. et al. Quanteda: An R package for the quantitative analysis of textual data. Journal of Open Source Software, v. 3, n. 30, p. 774, 2018

BIBER, D.; CONRAD, S.; REPPEN, R. Corpus linguistics: investigating language structure and use. Cambridge; New York: Cambridge University Press, 1998.

BREZINA, V.; MCENERY, T.; WATTAM, S. Collocations in context: A new perspective on collocation networks. International Journal of Corpus Linguistics, v. 20, n. 2, p. 139-173, 2015.

DAFONTE-GÓMEZ, Alberto. News Media and the Emotional Public Sphere| Audiences as Medium: Motivations and Emotions in News Sharing. International journal of communication, v. 12, p. 2133-2152, 2018.

DOS SANTOS CARVALHO, S. M.; DE BRITO SAMPAIO, M. P. Fact-cheking no $2^{\circ}$ turno das eleições (2018): análise das agências Lupa, Comprova, Aos Fatos e Pública. Anais de Resumos Expandidos do Seminário Internacional de Pesquisas em Midiatização e Processos Sociais, v. 1, n. 4, 2020.

ESIMAJE, A. U.; HUNSTON, S. What is corpus linguistics? In: ESIMAJE, A. U.; GUT, U.; ANTIA, B. E. (Eds.). Studies in Corpus Linguistics. Amsterdam: John Benjamins Publishing Company, v. 88, p. 8-35, 2019.

GABLASOVA, D.; BREZINA, V.; MCENERY, T. Collocations in Corpus-Based Language Learning Research: Identifying, Comparing, and Interpreting the Evidence: Collocations in Corpus-Based Language Learning Research. Language Learning, v. 67, n. S1, p. 155-179, 2017.

HALLIDAY, M. A. K. Language as social semiotic: the social interpretation of language and meaning. London: University Park Press, 1978.

HALLIDAY, M. A. K.; MATTHIESSEN, C. M. I. M. Halliday's Introduction to Functional Grammar. 3. ed. Hodder Education, 2004.

HASAN, R. Towards a paradigmatic description of context: systems, metafunctions, and semantics. Functional Linguistics, v. 1, n. 9, p. 1-54, 2014.

HUNSTON, S. Semantic prosody revisited. International Journal of Corpus Linguistics, v. 12, n. 2, p. 249-268, 27 jun. 2007.

KHRIYENKO, O. Propaganda Barometer: A Supportive Tool to Improve Media Literacy Towards Building a Critically Thinking Society. GSTF Journal on Computing, v. 6, n. 1, 2018.

KRESS, G. Against Arbitrariness: The Social Production of the Sign as a Foundational Issue in Critical Discourse Analysis. Discourse \& Society, v. 4, n. 2, p. 169-191, 1993.

LIMA-LOPES, R. E. DE. Artes, Militância e Ciência das Redes. Letras em Revista, v. 10, n. 01, p. 141-156, 2019.

LIMA-LOPES, R. E. DE. Oficina de Introdução à Linguística do Corpus: Relato de Experiência. Anais do VIII Escola Brasileira de Linguística Computacional \& XIII Encontro de Linguística do Corpus. Anais... In:VIII ESCOLA BRASILEIRA DE LINGUÍSTICA COMPUTACIONAL \& XIII ENCONTRO DE LINGUÍSTICA DO CORPUS. João Pessoa, Brasil: Editora Edgard Blücher, mar. 2016Disponível em: <10.5151/sosci-viiieblc-xiii-elc05_artigo_02>. Acesso em: 13 jul. 2020

LIMA-LOPES, R. E.; PIMENTA, I. S. \#Mulheresnofutebol: transitividade e avaliatividade na identificação de padrões sexistas. Humanidades \& Inovação, v. 4, n. 6, p. 116-131, 2017.

LIMA-LOPES, R. E.; VIAN JR, O. The Language of Evaluation (resenha). Revista D.E.L.T.A, v. 2, n. 23, p. 371-381, 2007.

MARTIN, J. R. What kind of structure? Interpersonal meaning and prosodic realization across strata. Word, v. 59, n. 1-2, p. 111-141, 2008. 
MARTIN, J. R.; WHITE, P. R. The language of evaluation. Basingstoke: Palgrave Macmillan, 2005.

MERCURI, K. T.; LIMA-LOPES, R. E. Discurso de ódio em mídias sociais como estratégia de persuasão popular. Trabalhos em Linguística Aplicada, Campinas, SP, v. 59, n. 2, p. 1216-1238, 2020. Disponível em: <https://periodicos.sbu.unicamp.br/ojs/index.php/tla/article/view/8658475>. Acesso em: 18 dez. 2020.

OLIVEIRA, D. M. O Sistema de Avaliatividade: Aspectos teóricos e práticos. Revista Fórum Identidades, 2014.

PALACIOS, M. Fake news e a emergência das agências de checagem: terceirização da credibilidade jornalística? In: MARTINS, M. L.; MACEDO, I. M. (org.) Políticas da língua, da comunicação e da cultura no espaço lusófono. Braga: Edições Húmus, 2019, p. 77-90.

ROGERS, R. Digital Methods Initiative. Disponivel em: <https://wiki.digitalmethods.net/Dmi/ToolDatabase>. Acesso em: 30 mar. 2020.

SHAROFF, S. Corpus and systemic functional linguistics. In: BARTLETT, T.; O'GRADY, G. (Eds.). The Routledge Handbook of Systemic Functional Linguistics. 1. ed. London/New York: Routledge, 2017.

SILGE, J.; ROBINSON, D. Text mining with R: a tidy approach. First edition ed. Beijing/Boston: O’Reilly, 2017.

SINCLAIR, J. Corpus, Concordance, Colocation. Oxford: Oxford Universiy Press, 1991.

SLOVIC, P., FINUCANE, M. L., PETERS, E., MACGREGOR, D. G. The affect heuristic. European Journal of Operational Research, v. 177, p. 1333-1352, 2007.

STUBBS, M. British Traditions in Text Analysis: Firth, Halliday and Sinclair. In: Text and corpus analysis. London: Blackwell, p. 23-50, 1996.

TANDOC JR, E.; LIM, W.; LING, R. Defining "fake news" A typology of scholarly definitions. Digital journalism, v. 6, n. 2, p. 137-153, 2018

THORSON, E. Changing Patterns of News Consumption and Participation. Information, Communication and Society, v. 11, n. 4, p. 473-489, 2008. TOMPSON, G.; ALBA-JUEZ, L. (Ed.) Evaluation in context. John Benjamins Publishing Company, 2014

TRIBBLE, C. What are concordances and how are they used? In: O'KEEFFE, A.; MCCARTHY, M. (Eds.) The Routledge Handbook of Corpus Linguistics. [s.I.] Routledge, 2010.

TUMBE, C. Corpus linguistics, newspaper archives and historical research methods. Journal of Management History, v. 25, n. 4, p. 533-549, 2019.

VIAN JR, O. O Sistema de Avaliatividade e os Recursos para a Gradação em Língua Portuguesa: Questões Terminológicas e de Instanciação. Revista D.E.L.T.A, n 25, v. 1, p. 99-129, 2009.

WHITE, P. Valoração: a linguagem da avaliação e da perspectiva. Revista Linguagem em (Dis)curso. Tubarão, v. 4, n. esp, p. 178-205, 2004. Disponível em: <http://www.portaldeperiodicos.unisul.br/index.php/Linguagem_Discurso/article/view/295 >. Acesso em 02 jan. 2020. 